\title{
A STUDY OF WELDING OF HETEROGENOUS POLYCARBONATE SUBSTANCES UTILIZING HYBRID FILAMENTS OF FUSED DEPOSITION MODELING
}

\author{
Afroza Bano ${ }^{a}$, Manish Kumar Gupta ${ }^{b^{*}}$ \\ ${ }^{a}$ Research Scholar, Department of Mechanical Engineering, School of Engineering, RIMT \\ University, Mandigobindgarh, Punjab, India - 147301 \\ ${ }^{\mathrm{b}}$ Assistant Professor, Department of Mechanical Engineering, School of Engineering, RIMT \\ University, Mandigobindgarh, Punjab, India - 147301 \\ *Corresponding Email ID: manishgupta@rimt.ac.in
}

\begin{abstract}
Friction-based welding is one of the most cost-effective and dependable methods for joining thermoplastics. However, there has been minimal work that has demonstrated the procedure/methods/equipment for welding two distinct types of thermoplastics. There is, nevertheless, a significant possibility of connecting the various thermoplastic materials by matching their melt flow index (MFI). One way for modifying the MFI is to reinforce it with micro/nano sized fillers. Fused deposition modelling (FDM) is a fast prototyping technology that employs thermoplastic-based filament to print components. The current study focuses on connecting aluminium (Al) metal powder reinforced acrylonitrile butadiene styrene (ABS) and polyamide 6 (PA6) thermoplastic substrates (3D printed by FDM) utilising friction welding (FW) / friction stir welding (FSW) / friction stir spot welding (FSSW). It was observed that the PA6 with 50\% Al fillers (PA6-50\% Al) and ABS matrix with 15\% Al fillers (ABS-15\% Al) produced MFIs of $11.97 \mathrm{~g} / 10 \mathrm{~min}$ and $11.57 \mathrm{~g} / 10 \mathrm{~min}$, respectively.
\end{abstract}

Keywords: FDM, MFI, FSW, twin screw extrusion, thermoplastics, ABS, PA6.

\section{Introduction}

Rapid prototyping (RP) has emerged as one of the most potent approaches, with a wide range of applications and significant cost savings. Today's world requires low-cost, highprecision goods and processes with greater production values (Kumar et al., 2012). In the last three decades, polymers have arisen as an alternative to metals, alloys, and some non-metals due to their superior durability, cost efficiency, better micro structural and mechanical characteristics, and ease of fast prototyping. The current age is focused on the use of thermoplastics or thermoplastic composites in nearly every application area in order to meet demand and necessity. Rapid prototyping is currently used in a variety of sectors, including polymer waste management, medical implant preparations, welding fabrication, structural applications, and turbine blade preparations, as well as the automotive and aerospace industries. The notion of fast prototyping is widely recognized in the electrical sector, where circuits such as bread boards are 
created using a 3D printer or fused deposition modeling. Over the previous four decades, FDM technology has progressed with the introduction of series of FDM equipment such as the FDM Titan, FDM Dimension, FDM Vantage, FDM Maxum, FDM 3000, and FDM Prodigy Plus (Bakar et al., 2010). Kumar et al. (2012) demonstrated how the FDM process works by dispensing two materials: one for building the component and the other for a disposable support framework. The material comes on a spool from a roll of plastic filament. The filament is fed into a temperature-controlled extrusion head and heated to a semi-liquid condition to produce the desired component. The head precisely extrudes and guides the material onto a fixtureless base in ultra-thin layers. The nozzle is controlled via a digital interface that allows the flow of melted material to be switched on and off at the desired spot. A plastic 3D model is created by laminating the hardened material to the previous layer one strand at a time. The system draws the model one layer at a time in the $\mathrm{X}, \mathrm{Y}$, and $\mathrm{Z}$ axes. The filament is extruded in a thin ribbon shape, which ensures that the filaments are bonded together at each layer (Liou, 2008). A road is the extruded filament that is placed onto the platform (Grimm, 2003; Bellini et al., 2004). The FDM method is seen schematically in Fig. 1.

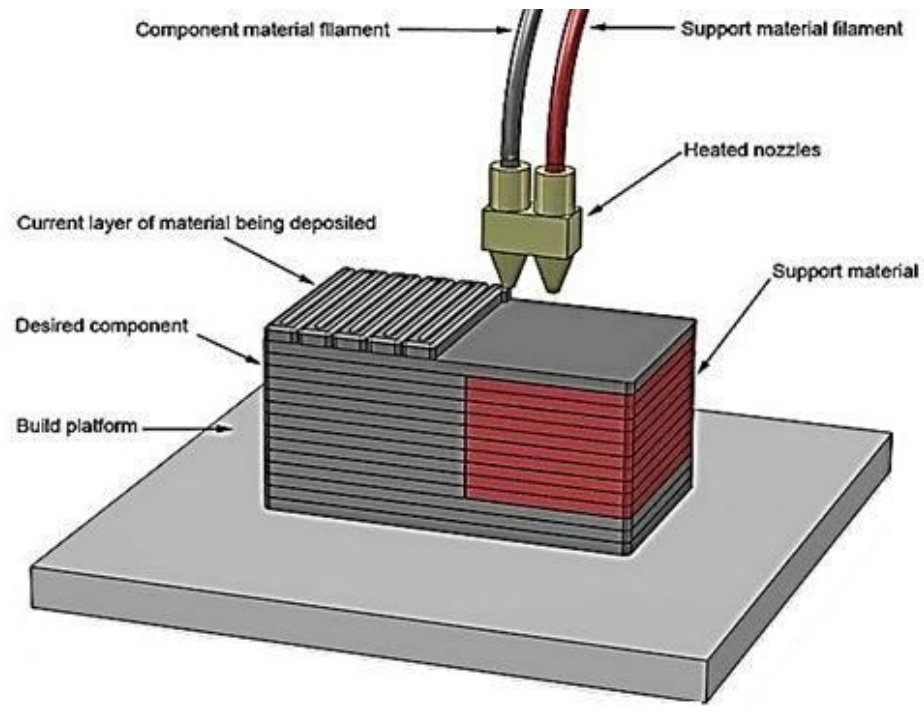

Fig. 1. Rapid prototyping through FDM

After being piled by another layer of road on the platform, a road immediately solidifies. A substrate is a previously deposited road that will be layered by the subsequent road. Overhanging geometries have support structures that are automatically produced and then broken away from the item (Upcraft and Fletcher, 2003). The FDM process begins with the import of a model's.STL file into pre-processing software. The 3D model is divided into tiny layers using this computer programme. Process parameters such as tip size, material type, and cutting speed are entered automatically, and the machine's control file is created 
Many challenges face the creation of FDM feedstock wire, including composition with a relative melt flow index, uniform filler distribution in plastic, and continuous wire extrusion, to name a few. Extruder deposition process (EDP) is a polymer extrusion method developed by Reddy et al. (2007) that deposits material on a computer-controlled positioning system to create components. The influence of factors such as nozzle temperature, chamber temperature, and road gap on bond strength and surface quality was examined by the researchers.

\section{METHODOLOGY}

Friction-based welding is one of the most cost-effective and dependable methods for connecting thermoplastics that are comparable. However, there has been minimal work that has demonstrated the procedure/methods/equipment for welding two distinct types of thermoplastics. There are, nevertheless, substantial potential for connecting the various thermoplastic materials by matching their MFI. One way for modifying the MFI is to reinforce it with micro/nano sized fillers. FDM is a fast prototyping technology that employs thermoplastic-based filament to print components. To prepare hybrid filament wire comprising of PA6, ABS polymer, PA6+Al (powder) and $\mathrm{ABS}+\mathrm{Al}$ (powder) are used with screw extrusion process. The goal of this research is to create FDM feedstock filament from two distinct thermoplastic composites that must be compatible in terms of thermal, mechanical, melt flow, and morphological characteristics for friction-based joining. For the production of composite feedstock filament, commercial grade ABS and PA6 were obtained, followed by a twin screw extrusion method. Because of their mechanical, chemical, and thermal properties, ABS and PA6 have different material characteristics. The MFI, specific heat capacity, chemical resistance, melting point, and mechanical strength of these thermoplastic materials vary significantly (Table 1). Al is the most common metal and has a high specific heat capacity and a low melting point, it was purchased in the form of 300 mesh size (about 50m grain size) particle sized from Shiva Chemical Pvt Ltd., Ludhiana, India for thermoplastic matrix reinforcement. Electrolytic Al metal powder (size: $50 \mathrm{~m}$ ) has been chosen for this research due to their properties such as thermal conductivity (almost twice of iron powder), corrosive resistance to prevent oxide development, Low melting points, high ductility, and light weights and Al and its alloys have a well-established FSW method etc. By using a differential scanning calorimetric (DSC) system, the melting points of these thermoplastics were determined to be $190.00-193.49^{\circ} \mathrm{C}$ for $\mathrm{ABS}$ and $223.29^{\circ} \mathrm{C}$ for PA6. ABS has an MFI of $8.76 \mathrm{~g} / 10 \mathrm{~min}$ while PA6 has an MFI of $23.27 \mathrm{~g} / 10 \mathrm{~min}$, according to ASTM D1238. Batra Polymers Pvt Ltd, Ludhiana, India, provided the main recycled commercial grade ABS (Grade- EX58) and PA6 (Grade- PX99848).

The impact of process parameters on feed stock filament characteristics was investigated using twin screw extrusion as a melt processing method in this research. Temperature is one of the most important variables affecting material characteristics during the extrusion process. As a consequence, it was necessary to assess the temperature ranges at which extrusion should be 
performed, which had to be determined using DSC findings. Thermal analysis was used to determine the melting peak temperature of recycled PA6 granules. The usual DSC setup evaluates the behaviour of applied samples by using standard samples as standards, both of which are contained in a metallic crucible (Al or platinum). The DSC sensor employs two crucibles for heating and cooling, one for reference and the other for sample.

The extrusion temperature is the most essential characteristic for dimensional accuracy and material stability in extrusion of any metals, alloys, and thermoplastics. For all of the chosen compositions, DSC findings indicate that peak melting points were achieved in the range of 217.31-221.06. The extrusion temperature values used in this research were chosen based on a variety of factors, including (a)The DSC findings were achieved in a static (controlled) setting, while twin screw extrusion was carried out in a dynamic environment (less controlled). Because of the dynamic environmental circumstances, such as the effects of external temperature, light, and humidity, the extrusion temperature must be kept higher than the DSC values obtained; (b) The DSC findings were calculated for a small amount of material (e.g. 3-15mg), while extrusion was done for a large amount of material (e.g. 10-50 gm.). As a result, during the extrusion process, heat sinking occurs. This may be one of the reasons why the extrusion temperature was chosen to be higher than the DSC melting peak findings and (c) Al powder reinforcement causes heat absorption owing to higher heat capacity behaviour. As a result, the extrusion temperature must be maintained based on the results of pilot experiments. The temperature has been chosen in this instance based on the results of a pilot experiment (e.g. dimensional stability). The entire filaments were extruded through nozzle with diameter of $1.50-1.75 \mathrm{~mm}$.

Table 1. Mechanical, chemical and thermal properties of ABS and PA6

\begin{tabular}{|c|c|c|}
\hline Properties & ABS & PA6 \\
\hline $\begin{array}{c}\text { Tensile strength } \\
\left(\mathrm{N} / \mathrm{mm}^{2}\right)\end{array}$ & $3.52-15.27$ & $4.22-16.88$ \\
\hline $\begin{array}{c}\text { Flexural strength } \\
\left(\mathrm{N} / \mathrm{mm}^{2}\right)\end{array}$ & $189.88-267.24$ & $274.27-773.59$ \\
\hline Chemical resistance & Poor to fair & Good to excellent \\
\hline $\begin{array}{c}\text { Glass Transition } \\
\text { Temperature }\left({ }^{\circ} \mathrm{C}\right)\end{array}$ & 105 & $2150 \mathrm{C}$ \\
\hline $\begin{array}{c}\text { Melting point }\left({ }^{\circ} \mathrm{C}\right) \\
\text { melting(amorphous })\end{array}$ & $\begin{array}{c}\text { No true } \\
\text { N }) \mathrm{n}\end{array}$ & $(\mathrm{C} 6 \mathrm{H} 11 \mathrm{NO}) \mathrm{n}$ \\
\hline $\begin{array}{c}\text { Chemical formula } \\
(\mathrm{C} 8 \mathrm{H} 8 \cdot \mathrm{C} 4 \mathrm{H} 6 \cdot \mathrm{C} 3 \mathrm{H} 3\end{array}$ & 1.08 \\
\hline $\begin{array}{c}\text { Density } \\
\left(\mathrm{g} / \mathrm{cm}^{3}\right)\end{array}$ & $0.9-1.53$ & \\
\hline
\end{tabular}




\section{Results and discussion}

The components were fastened to the FSW setup (vertical milling machine with dynamometer and thermal imaging) and the welding was completed. The joints failed to form, and the welding of these two virgin thermoplastics was unsuccessful. During the FSW process, it was discovered that ABS was melted first, whereas PA6 was not melted at all. Those findings revealed that the melting temperature and melt flow difference between ABS and PA6 should exist. Similarly, it was discovered in a pilot trial using a standard lathe (chosen for FW) that connecting virgin ABS and virgin PA6 was not possible (see Fig. 2).

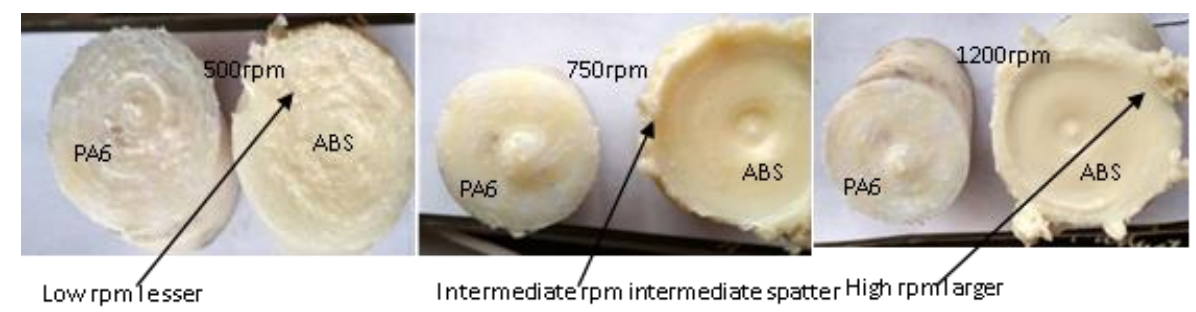

Fig.2. Joint failure due to material non-compatibility

Table 2. MFI variation of ABS and PA6 with proportions of Al metal filler

\begin{tabular}{|c|c|c|c|c|c|c|c|c|c|c|c|}
\hline $\begin{array}{l}\text { Trial } \\
\text { No. }\end{array}$ & $\begin{array}{l}\text { Pure } \\
\text { ABS }\end{array}$ & $5 \%$ & $10 \%$ & $15 \%$ & $20 \%$ & $25 \%$ & $30 \%$ & $35 \%$ & $40 \%$ & $45 \%$ & $50 \%$ \\
\hline 1 & 9.05 & 8.11 & 10.5 & 11.4 & 12.5 & 10.4 & 10.26 & 9.37 & 9.33 & 7.23 & 7.09 \\
\hline 2 & 8.39 & 10.39 & 10.6 & 11.8 & 12.5 & 11.1 & 10.59 & 10.6 & 8.87 & 7.43 & 6.81 \\
\hline 3 & 8.86 & 9.71 & 9.27 & 11.5 & 13 & 11 & 10.01 & 9.98 & 9.23 & 8.04 & 5.56 \\
\hline Avg. & 8.76 & 9.4 & 10.1 & 11.6 & 12.6 & 10.8 & 10.28 & 9.99 & 9.14 & 7.56 & 6.48 \\
\hline $\begin{array}{l}\text { Trial } \\
\text { No. }\end{array}$ & $\begin{array}{l}\text { Pure } \\
\text { PA6 }\end{array}$ & $5 \%$ & $10 \%$ & $15 \%$ & $20 \%$ & $25 \%$ & $30 \%$ & $35 \%$ & $40 \%$ & $45 \%$ & $50 \%$ \\
\hline 1 & 23.58 & 25.17 & 29.8 & 33.1 & 35.2 & 38.9 & 36.85 & 31.8 & 20.2 & 15.02 & 10.76 \\
\hline 2 & 23.27 & 23.01 & 30.6 & 30.9 & 34.5 & 33.6 & 35.39 & 29.9 & 21.1 & 19.27 & 12.33 \\
\hline 3 & 22.98 & 25.4 & 29.1 & 30.9 & 33.5 & 35.5 & 36.88 & 28.5 & 23.2 & 16.94 & 12.84 \\
\hline Avg. & 23.27 & 24.52 & 29.8 & 31.6 & 34.4 & 36 & 36.37 & 30.1 & 21.5 & 17.07 & 11.97 \\
\hline
\end{tabular}

\section{MFI analysis}

In the instance of ABS polymer matrix, increasing the Al metal filler up to $20 \%$ resulted in a substantial rise in MFI, but beyond this level, there was a significant reduction in MFI. For the 
PA6 polymer matrix, a rise in MFI was seen up to $30 \% \mathrm{Al}$ filler, but beyond that, an increase in Al fillers resulted in a reduction in MFI. For the joining/welding application, the MFI analysis was used to determine the Al filler concentration. It should be remembered that the two distinct polymer properties that determine the characteristics of polymers are molecular weight and density. The density of the polymer matrix is an intrinsic characteristic that has no bearing on the melt flow rate determination. The molecular weight of a polymer is an intriguing characteristic that virtually guarantees the melt flow rate. Lower melt flow properties are ensured by higher molecular weight. Because a polymer's long carbon chain is branched, its molecular weight rises, while a linear or non-branched carbon chain has a smaller molecular weight (http://www.ptonline.com). MFI of ABS matrix was enhanced up to $20 \% \mathrm{Al}$ content (by weight) in this research, which may be related to the density effect. However, the melt flow has reduced in recent years, owing to a rise in molecular weight. This may be due to carbon chain branching/elongation, with the impact of $\mathrm{Al}$ powder reinforcement exceeding $20 \%$ (by weight) in the current environment. MFI of $11.97 \mathrm{~g} / 10 \mathrm{~min}$ and $11.57 \mathrm{~g} / 10 \mathrm{~min}$ were obtained for PA6 matrix with $50 \% \mathrm{Al}$ filler and ABS matrix with $15 \% \mathrm{Al}$ filler, respectively. Because the MFI values were nearly identical at these proportions (PA6 with $50 \% \mathrm{Al}$ and $\mathrm{ABS}$ with $15 \% \mathrm{Al}$ ), these amounts of Al filler were judiciously chosen for the production of feedstock filament for the fabrication of functional prototypes using FDM for friction welding applications.

\section{DSC analysis}

Because ABS is an amorphous thermoplastic, a melting range of $190.55-201.22^{\circ} \mathrm{C}$ was determined as a tiny melting curve developed towards the conclusion of continuous heating. Another experiment was carried out to determine the DSC as thermal characteristics of natural commercial grade PA6 polymers under controlled endothermic and exothermic changes. In the case of natural PA6, a genuine melting curve developed, with melting points of $223.29^{\circ} \mathrm{C}$ and $219.35^{\circ} \mathrm{C}$ in the first and second heating cycles, respectively, with PA6 solidifying from $192.57^{\circ} \mathrm{C}$. In comparison to ABS, the PA6 material had a higher specific heat capacity.

Another comparison between ABS and PA6 may be made based on their melting ranges, with PA6 melting at a higher temperature than ABS. Because friction welding needs comparable thermal and rheological characteristics to accomplish joining between different materials, the significant disparity in thermal properties between virgin ABS and virgin PA6 limited their compatibility for friction welding. In terms of MFI, the melt flow characteristic guaranteed ABS and PA6 compatibility at ABS with 15\% Al filler and PA6 with 50\% Al filler. The impact of fixed filler content on thermal characteristics was investigated in order to guarantee the compatibility of these two polymers. The thermal characteristics of ABS-15 percent Al showed an improvement in melting range between 217.31-218.11oC and a substantial reduction in specific heat capacity. Thermal study was performed on the PA6-50 percent Al matrix after the thermal characteristics of ABS-15 percent Al were evaluated. The PA6-50 percent Al was tested

under the same controlled circumstances as the ABS-15 percent Al was tested under. The thermal study of PA6-50 percent Al revealed that it has a melting range that is almost identical to 
ABS-15\%Al. Both the ABS-15Al and the PA6-50 percent Al had a high melting point of 217.31$221.06^{\circ} \mathrm{C}$. The inclusion of $\mathrm{Al}$ fillers had a significant impact since their specific heat capacity rate was decreased when filler materials were added. As a result of these rheological and thermal studies of ABS and PA-6 materials, a requirement for compatibility at a certain Al filler level for friction welding applications may be readily determined. The melt flow characteristics of ABS and PA6 materials were adjusted and brought into a comparable range at a given filler level. The inclusion of filler at a particular amount has led to their melting point and specific heat capacity being comparable. Because of the thermal analysis of these chosen proportions/compositions, ABS-15 percent $\mathrm{Al}$ and $\mathrm{PA} 6-50$ percent $\mathrm{Al}$ are mechanically compatible for friction welding of these two thermoplastics.

\section{Twin Screw extrusion}

The input variable was determined as the outcomes of DSC results for the twin screw extruder setup according to Taguchi L9 orthogonal array to select the optimum process parameters toward preparations of composite feedstock filament for the FDM setup, as the melting range was obtained from DSC analysis for proposed composition of Al metal filler with polymer matrix. The input process parameter was chosen based on the homogeneity of the filament extruded during the pilot experiment. Apart from temperature, the applied load and screw speed were the two other machining factors that had a considerable impact on the characteristics of the feedstock filaments produced. Because the role of applied load and screw speed in twin screw extrusion contributed to mixing, these parameters were carefully chosen. Temperatures of 220, 225, and 230 degrees Celsius, applied loads of 10, 15, and 20 kilogrames, and screw speeds of 20,25, and 30 revolutions per minute were chosen for studies of mechanical characteristics of ABS-15Al. During pilot testing, it was discovered that PA6-50Al feedstock filaments were produced consistently at temperatures ranging from 240 to $250 \mathrm{oC}$ and loads ranging from $10-15 \mathrm{~kg}$. As a result, the values of all three parameters have been set within a certain range (See Table 3 and Table 4)

Table 3. Control log of experimentation as per Taguchi L9 O.A for ABS-15\% Al

\begin{tabular}{|c|c|c|c|}
\hline $\begin{array}{c}\text { Experiment } \\
\text { no. }\end{array}$ & $\begin{array}{c}\text { Temperature } \\
\left({ }^{(} \mathbf{C}\right)\end{array}$ & Applied Load (kg) & $\begin{array}{c}\text { Screw Speed } \\
(\mathbf{R P M})\end{array}$ \\
\hline 1 & 220 & 10 & 20 \\
\hline 2 & 220 & 15 & 25 \\
\hline 3 & 220 & 20 & 30 \\
\hline 4 & 225 & 10 & 25 \\
\hline 5 & 225 & 15 & 30 \\
\hline 6 & 225 & 20 & 20 \\
\hline 7 & 230 & 10 & 30 \\
\hline 8 & 230 & 15 & 20 \\
\hline 9 & 230 & 20 & 25 \\
\hline
\end{tabular}


Table 4 Control log of experimentation as per Taguchi L9 O.A for PA6- 50\%Al

\begin{tabular}{|c|c|c|c|}
\hline $\begin{array}{c}\text { Experiment } \\
\text { no. }\end{array}$ & Temperature $\left({ }^{\circ} \mathbf{C}\right)$ & $\begin{array}{c}\text { Applied } \\
\text { load (Kg) }\end{array}$ & $\begin{array}{c}\text { Screw } \\
\text { Speed(rpm) }\end{array}$ \\
\hline 1 & 240 & 10 & 15 \\
\hline 2 & 240 & 15 & 20 \\
\hline 3 & 240 & 20 & 25 \\
\hline 4 & 245 & 10 & 20 \\
\hline 5 & 245 & 15 & 25 \\
\hline 6 & 245 & 20 & 15 \\
\hline 7 & 250 & 10 & 25 \\
\hline 8 & 250 & 15 & 15 \\
\hline 9 & 250 & 20 & 20 \\
\hline
\end{tabular}

\section{Mechanical Properties and influences of extrusion parameters}

Tensile Mechanical properties (break strength, peak strength, and Shore D hardness) and associated SN ratios are shown in table 5. The highest strength of the tensile test specimen before breakage is known as peak strength. Fracture strength was found to be lower than ultimate (peak) strength for all specimens examined. It was discovered that the ABS-15 percent $\mathrm{Al}$ feedstock filaments had the highest strength values in sample no. 3 and the lowest in sample no. 8. Similarly, the highest values for PA6-50 percent Al were found for experiment sample no. 6 and the lowest values for experiment sample no. 1

Table 5 Mechanical properties of friction welded ABS-15\%Al and PA6-50\% Al specimen

\begin{tabular}{|c|c|c|c|c|c|}
\hline $\begin{array}{c}\text { Experiment } \\
\text { no. }\end{array}$ & $\begin{array}{c}\text { Tensile } \\
\text { strength } \\
\text { break } \\
\text { (Mpa }\end{array}$ & $\begin{array}{c}\text { Tensile } \\
\text { strength } \\
\text { peak } \\
\text { (Mpa) }\end{array}$ & $\begin{array}{c}\text { Flexural } \\
\text { strength } \\
\text { break(Mpa) }\end{array}$ & $\begin{array}{c}\text { Flexural } \\
\text { strength } \\
\text { peak } \\
\text { (Mpa) }\end{array}$ & $\begin{array}{c}\text { Shore D } \\
\text { hardness }\end{array}$ \\
\hline 1 & 57 & 63.3 & 143.7 & 159.7 & 79 \\
\hline 2 & 50.4 & 56 & 135 & 150 & 78.5 \\
\hline 3 & 27.6 & 30.7 & 110.9 & 123.2 & 77 \\
\hline 4 & 82.5 & 91.6 & 243.1 & 270.1 & 80.5 \\
\hline 5 & 74.8 & 83.1 & 222.6 & 247.4 & 80 \\
\hline 6 & 64.7 & 71.9 & 144.8 & 160.9 & 79.5 \\
\hline 7 & 92.2 & 102.5 & 270.3 & 300.4 & 82.5 \\
\hline 8 & 90.5 & 100.5 & 230.1 & 255.7 & 81.5 \\
\hline 9 & 81.6 & 90.7 & 177.7 & 197.4 & 81 \\
\hline
\end{tabular}




\section{CONCLUSIONS}

The research includes hybrid methods for developing melt-processed thermoplastic composite materials with improved welding properties. The findings were produced in the study as follows:

1. The Al filler concentration for the joining/welding application was chosen based on the MFI study. MFI of $11.97 \mathrm{~g} / 10 \mathrm{~min}$ and $11.57 \mathrm{~g} / 10 \mathrm{~min}$ were obtained for PA6 matrix with 50\% Al filler and ABS matrix with 15\% Al filler, respectively. Because the MFI values were nearly identical at these proportions (PA6 with 50\% Al and ABS with 15\% Al), these amounts of Al filler were judiciously chosen for the production of feedstock filament for the fabrication of functional prototypes using FDM for friction welding applications.

2. The inclusion of filler at a particular amount has led to their melting point and specific heat capacity being comparable. Thermal study of these chosen proportions/compositions confirmed that ABS-15 percent $\mathrm{Al}$ and PA6-50 percent $\mathrm{Al}$ are thermally compatible for friction welding of these two thermoplastics.

3. MIAS was used to make the observation about the porosity of the fracture filaments. The porosity value measured at the filament surface is inversely related to the mechanical strength of feedstock filament.

4. The \% porosity of the photomicrographs was measured and correlated with mechanical strength.

5. The highest mechanical strength was achieved for ABS-15 percent Al. This may be because at the lowest temperature and maximum rpm and load, the mixing of $\mathrm{Al}$ and ABS was better than at the middle temperature and highest rpm.

6. The photomicrographs show that filament samples with higher mechanical strength have less porosity, while filament samples with lower mechanical strength have more porosity on the surface.

\section{REFERENCES}

1) Ashish, B. I. S. T., Saini, J. S., \& Sharma, B. (2016),-A review of tool wear prediction during friction stir welding of aluminium matrix compositell,Transactions of Nonferrous Metals Society of China, Vol. 26, No. 8, pp. 2003-2018.

2) Attallah, M.M. and Preuss, M. (2012), - Inertia friction welding (IFW) for aerospace applications $\|$, Welding and Joining of Aerospace Materials, pp.25-74. Book DOI: 10.1533/9780857095169.1.25

3) Aval, H. J. (2015), - Microstructure and residual stress distributions in friction stir welding of dissimilar aluminium alloysl, Materials \& Design, Vol. 87, pp. 405413. 
4) Aydin, M. (2010), -Effects of welding parameters and pre-heating on the friction stir welding of UHMW-polyethylene", Polymer-Plastics Technology and Engineering, Vol. 49, No. 6, pp. 595-601.

5) Azarsa, E. And Mostafapour, A. (2014), -Experimental investigation on flexural behavior of friction stir welded high density polyethylene sheetsll,Journal of Manufacturing Processes, Vol. 16, No. 1, pp. 149-155.

6) Azarsa, E. andMostafapour, A. (2013), - On the feasibility of producing polymer- metal composites via novel variant of friction stir processing\|, Journal of Manufacturing Processes, Vol. 15, No. 4, pp. 682-688.

7) Azhiri, R. B., Tekiyeh, R. M., Zeynali, E., Ahmadnia, M., \& Javidpour, F. (2018),-Measurement and evaluation of joint properties in friction stir welding of ABS sheets reinforced by nanosilica additionll, Measurement, Vol. 127, pp. 198-204.

8) Bagheri, A., Azdast, T., \&Doniavi, A. (2013),-An experimental study on mechanical properties of friction stir welded ABS sheetsll,Materials \& Design, Vol. 43, pp. 402- 409.

9) Bakar, N.S.A., Alkahari, M.R. and Boejang, H. (2010), -Analysis on fused deposition modeling performancell, Journal of Zhejiang University ScienceA, Vol. 11, No. 12, pp. 972-977.

10) Banjare, P. N., Sahlot, P., \& Arora, A. (2017), -An assisted heating tool design for FSW of thermoplasticsll, Journal of Materials Processing Technology, Vol. 239, pp. 83-91.

11) Barcellona, A., Buffa, G., Fratini, L. and Palmeri, D. (2006), -On microstructural phenomena occurring in friction stir welding of aluminum alloysll, Journal of Materials

12) Bedi, P., Singh, R., \& Ahuja, I. S. (2018),-Investigations for Rapid Tooling Prepared With Waste Polymer-Based Hybrid Filamentl,Reference Module in Materials Science and Materials Engineering, doi:10.1016/B978-0-12-8035818.10401-1 
13) Bellini, A., Guceri, S. and Bertoldi, M. (2004), - Liquefier dynamics in fused depositionll,Journal of Manufacturing Science and Engineering, Vol. 126, No. 2, pp. 237-246.

14) Berretta, S., Davies, R., Shyng, Y.T., Wang, Y., Ghita, O., (2017),-Fused Deposition Modelling of high temperature polymers: Exploring CNT PEEK compositesll, Polymer Testing, Vol. 63, pp. 251-262.

15) Besler, F. A., Schindele, P., Grant, R. J., \& Stegmüller, M. J. (2016),-Friction crush welding of aluminium, copper and steel sheet metals with flanged edges\| Journal of Materials Processing Technology,Vol. 234, pp. 72-83.

16) Bevilacqua, M., Ciarapica, F. E., D_Orazio, A., Forcellese, A., \& Simoncini, M. (2017),॥ Sustainability Analysis of Friction Stir Welding of AA5754 Sheetsll,Procedia CIRP, Vol. 62, pp. 529-534.

17) Bilici, M.K., Yukler, A.I. andKurtulmus, M. (2011), -The optimization of welding parameters for friction stirs spot welding of high density polyethylene sheetsll,Materials\& Design, Vol. 32, No. 7, pp. 4074-4079.

18) Bilici,M.K. andYukler,A.I. (2012), - Influence of tool geometry and process parameters on macrostructure and static strength in friction stir spot welded polyethylene sheetsll,Materials\& Design, Vol. 33, pp. 145-152.

19) Boukraa, M., Lebaal, N., Mataoui, A., Settar, A., Aissani, M., \& Tala-Ighil, N. (2018),-Friction stir welding process improvement through coupling an optimization procedure and three-dimensional transient heat transfer numerical analysisll, Journal of Manufacturing Processes, Vol. 34, pp. 566-578.

20) Bozkurt, Y. (2012), - The optimization of friction stir welding process parameters to achieve maximum tensile strength in polyethylene sheetsl,Materials \& Design, Vol. 35, pp. 440-445.

21) Buchibabu, V., Reddy, G. M., \& De, A. (2017), -Probing torque, traverse force and tool durability in friction stir welding of aluminum alloysll,Journal of Materials Processing

22) Buffa, G., Baffari, D., Campanella, D., \&Fratini, L. (2016),-An Innovative Friction Stir Welding Based Technique to Produce Dissimilar Light Alloys to 
Thermoplastic Matrix Composite Joints॥,Procedia Manufacturing, Vol. 5, pp. 319331

23) Cabibbo, M., Forcellese, A., Simoncini, M., Pieralisi, M., \&Ciccarelli, D. (2016),-_Effect of welding motion and pre-/post-annealing of friction stir welded AA5754 joints॥,Materials \& Design, Vol. 93, pp. 146-159.

24) Cavaliere, P. (2013),-Friction stir welding of Al alloys: analysis of processing parameters affecting mechanical behaviourl,Procedia CIRP, Vol. 11, pp. 139-144.

25) Cavaliere, P., Nobile, R. andPanella, F (2006), - Mechanical and Microstructural Behaviour Of 2024-7075 Aluminium Alloy SheetsJoined by Friction Stir Welding\|,International Journal of Machine Tools \& Manufacture, Vol. 46, No. 6, pp. 588-594 